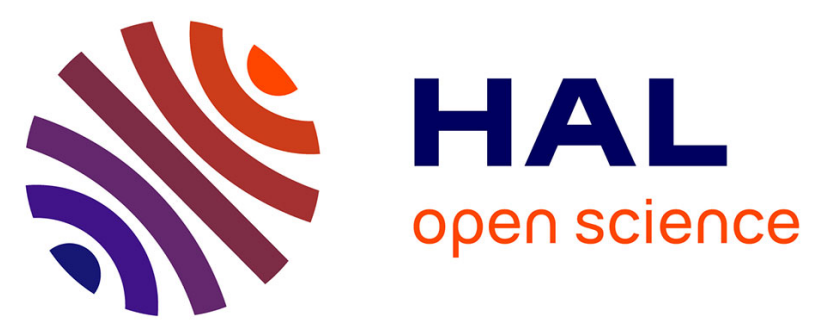

\title{
Resolution of an atropoisomeric naphthamide by second-order asymmetric transformation: A highly productive technique
}

Ryusei Oketani, Marine Hoquante, Clément Brandel, Pascal Cardinaël, Gérard Coquerel

\section{To cite this version:}

Ryusei Oketani, Marine Hoquante, Clément Brandel, Pascal Cardinaël, Gérard Coquerel. Resolution of an atropoisomeric naphthamide by second-order asymmetric transformation: A highly productive technique. Organic Process Research and Development, 2019, 23 (6), pp.1197-1203. 10.1021/acs.oprd.9b00133 . hal-02138812

\section{HAL Id: hal-02138812}

https://hal-normandie-univ.archives-ouvertes.fr/hal-02138812

Submitted on 3 Sep 2019

HAL is a multi-disciplinary open access archive for the deposit and dissemination of scientific research documents, whether they are published or not. The documents may come from teaching and research institutions in France or abroad, or from public or private research centers.
L'archive ouverte pluridisciplinaire HAL, est destinée au dépôt et à la diffusion de documents scientifiques de niveau recherche, publiés ou non, émanant des établissements d'enseignement et de recherche français ou étrangers, des laboratoires publics ou privés. 


\title{
Resolution of an atropoisomeric naphthamide by
}

\author{
second-order asymmetric transformation: A highly
}

productive technique

Ryusei Oketani, Marine Hoquante, Clément Brandel, Pascal Cardinael, Gérard Coquerel*

Université de Rouen Normandie, UFR des Sciences et Techniques, Laboratoire SMS-

EA3233, Place Emile Blondel, 76821 Mont-Saint-Aignan, France.

\begin{abstract}
Temperature-cycle-induced deracemization (TCID) has been widely studied in the field of chiral separation, ranging from fundamental research to applications. In this study, the secondorder asymmetric transformation (SOAT) of 2-methoxy-1-naphthamide in an azeotropic mixture of ethyl acetate and cyclohexane is compared with TCID, in terms of process productivity. The results indicate that the volumetric productivity using SOAT was over 100times higher than that using TCID, such that a scale-up by a factor of 10 was easily implemented.
\end{abstract}

Keywords: deracemization, second-order asymmetric transformation (SOAT), productivity, atropisomerism 


\section{Introduction}

Chiral separation is an important field of research because of the impact of chirality on the development of high-value materials (e.g., pharmaceuticals, agrochemicals, and optics). Crystallization is often the preferred chiral separation technique at industrial scales because it has a smaller carbon footprint and is cheaper than other methods like chromatography. ${ }^{1-3}$ Preferential crystallization (PC) is a chiral resolution technique that can be applied to a conglomerate-forming system. ${ }^{4}$ It is noteworthy that no racemization occurs during PC (i.e. enantiomers cannot interconvert), leading to the gradual enrichment of the enantiomeric excess of the solution in the counter enantiomer. This puts a limit in the yield of every single operation. The theoretical maximum yield after recycling several times the mother liquors is $50 \%$. By contrast, deracemization by crystallization is a promising chiral separation technique although it needs also a conglomerate-forming system, because it is performed under racemize conditions which steadily produce the desired enantiomer, leading to a theoretical yield of $100 \% .{ }^{5}$ In addition to this major advantage, deracemization by crystallization is quite facile. For example, temperature-cycle-induced deracemization (TCID) is a process that converts a racemic mixture of the substrate to a nearly pure enantiomer in the solid phase without any external chiral source through temperature cycling. ${ }^{1,6-11}$ 


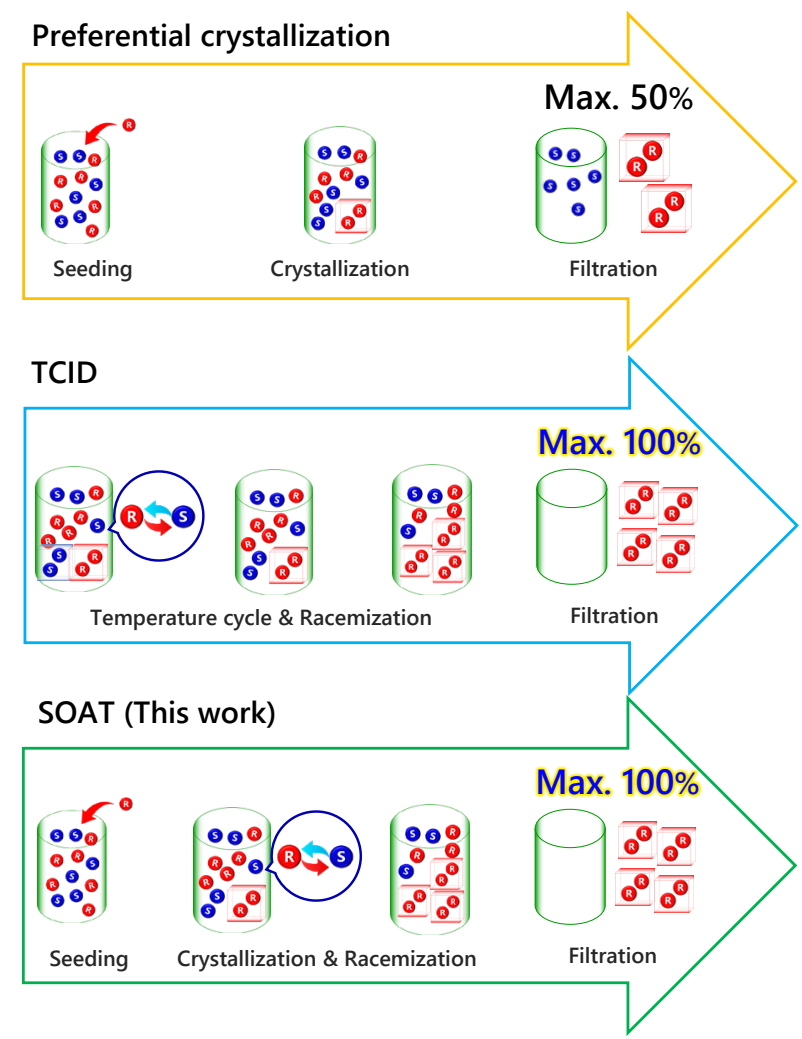

Scheme 1. Schematic representations of PC, TCID, and SOAT process.

Recently, we reported the TCID of atropoisomer 1 (Figure 1) and its racemization rate $\left(k_{1}\right){ }^{6}$ where we showed that the process productivity appears to be proportional to the racemization rate $\left(k_{1}\right)$, multiplied by the solubility. The productivity of a separation process is defined as the amount of enantiomer produced per unit time and unit volume of crystallizer or suspension. ${ }^{8,12}$

$$
\text { Productivity }=\frac{m_{\text {crop }} \times e e_{\text {final }}-m_{\text {seeds }}}{\text { time } \cdot \text { volume }} \text { (Eq. 1) }
$$

where $m_{\text {crop }}$ and eefinal are the mass and the enantiomeric excess of the collected crystals, respectively, and $m_{\text {seeds }}$ is the mass of the seed crystals. Although a few examples exhibit good productivity (for example, the PC of baclofen ${ }^{13}$ attained an average productivity of $69 \mathrm{~g} \mathrm{~h}^{-1} \mathrm{~L}^{-}$

${ }^{1}$ taking into account the equilibration time before crystallization), the typical productivity of PC ranges from 10 to $20 \mathrm{~g} \mathrm{~h}^{-1} \mathrm{~L}^{-1} \cdot{ }^{14,15} \mathrm{In}$ comparison, the productivity of TCID is as low as 
0.1-5.0 $\mathrm{g} \mathrm{h}^{-1} \mathrm{~L}^{-1}{ }^{6,8}$ Thus, although TCID can double the theoretical yield, the productivity of the process is almost one order of magnitude lower than that of PC.

The low productivity of TCID is obviously due to the associated long process times. Indeed, the usual minimum process duration for TCID is about 10 h..$^{7,8,16,17}$ In contrast, PC runs typically involve rapid cooling; thus, the process times are much shorter. It is therefore important to shorten process times to significantly improve the process productivities and achieve a process with high productivity.

The scaling up of PC often lead to problems in sub-operations, even when chiral crystallization is effective. In particular, the filtration step could affect the feasibility, and occasionally this kind of problem causes PC to fail. For example, laboratory-scale filtration can usually be completed in a reasonable amount of time, but large-scale production requires much longer. The PC process normally incorporates a quick filtration after the end of the entrainment because a longer crystallization period could trigger the nucleation of the counter-enantiomer and reduce the optical purity of the crop. Therefore, the time required for filtration with a scaled-up process could constitute a critical problem. By contrast, deracemization processes generally do not incur such a problem, since enantiomers are steadily interconverted in the solution. Moreover, the supersaturation of both enantiomers is always held close to 1 , thus the probability of the nucleation of the counter-enantiomer decreases. This feature eliminates the limitation incurred in the scaling up of the process and helps to apply the process in the industrial field.

Second-order asymmetric transformation (SOAT) is defined as a crystallization-induced asymmetric transformation during which the racemic mixture is converted into either a pure enantiomer or a mixture in which one enantiomer is present in excess. ${ }^{18}$ In other words, SOAT can be regarded as being a PC process under racemization conditions, as shown in Scheme 1 . 
As a hybrid of PC and deracemization, SOAT offers great promise as a process affording high yield and high productivity. To the best of our knowledge, there have been relatively few reports on the SOAT process and no studies have investigated the productivity of the process. ${ }^{19-}$ ${ }^{46}$ In the present study, we examined the application of the SOAT process to naphthamide $\mathbf{1}$ (Figure 1), a conglomerate-forming system that exhibits solid-state atropisomerism (i.e., it spontaneously racemizes in solution) at two different scales. In addition, we show that SOAT of this compound is more productive than that of regular TCID even if the two processes are comparable in term of interplay between homogeneous and heterogeneous equilibria. ${ }^{47}$

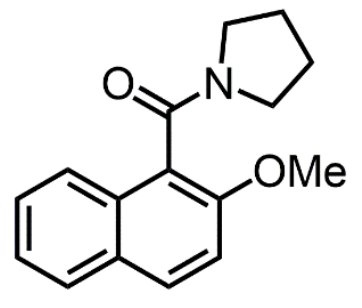

1

Figure 1. Chemical structure of naphthamide 1.

\section{Experimental methods}

Compound 1 was synthesized as described in our previous work. ${ }^{6}$ The solubility of $\mathbf{1}$ in a 45/55 (wt/wt) mixture of cyclohexane and ethyl acetate (Certified AR for Analysis, Fisher Chemical, France), was measured by a gravimetric method from $10-60{ }^{\circ} \mathrm{C}$. The temperature was controlled by a thermostat (F25-HL Cryostat, JULABO GmbH, Germany). Racemization kinetic constants $\left(k_{1}\right)$ of 1 from $10-45{ }^{\circ} \mathrm{C}$ were also measured over time using a polarimeter $(\mathrm{P}-$ 2000, Jasco France, France) at $365 \mathrm{~nm}$ with a Hg-lamp., 6,48

The TCID of $\mathbf{1}$ was performed by applying the following procedure. Compound $\mathbf{1}$ was completely dissolved by heating in $10 \mathrm{~mL}$ of an azeotropic mixture of ethyl acetate and cyclohexane $(55 / 45, \mathrm{wt} / \mathrm{wt})$ in a $30-\mathrm{mL}$ screw vial that contained a cross-type Teflon-coated stirring bar. Subsequently, the solution was cooled to $10-20{ }^{\circ} \mathrm{C}$ to induce spontaneous 
crystallization. Then, the suspension was held at $20{ }^{\circ} \mathrm{C}$ for $30 \mathrm{~min}$ to allow it to reach equilibrium. The heterogeneous mixture was stirred under the temperature-cycling conditions shown in Figure 2 for a maximum of 10 days. To confirm the scalability of the process, we performed TCID of $\mathbf{1}$ in 4 different scales of suspension density $\rho$, namely, 14.4, 36.0, 72.0, and $144 \mathrm{mg} \mathrm{mL}^{-1}$. Since the temperature cycle between 20 and $30{ }^{\circ} \mathrm{C}$ gives a $7.2-\mathrm{mg} \mathrm{mL}^{-1}$ dissolution-crystallization cycle, $50,20,10$, and $5 \%$ of the crystals were deliberately dissolved during the heating step. For the off-line monitoring of the deracemization experiments involving 1 , a small amount $(\sim 30 \mu \mathrm{L})$ of the suspension was drawn off and filtered through an $8 \varphi$ filter paper in a Kiriyama Rohto VB- 8 funnel. The collected crystals were dried under a vacuum, weighed, and then dissolved in $\mathrm{MeOH}\left(1.200 \mathrm{~mL}\right.$, HPLC grade) at $4{ }^{\circ} \mathrm{C}$. The enantiomeric excess was determined by comparing the optical rotations at $365 \mathrm{~nm}$ and $4{ }^{\circ} \mathrm{C}$ with the previously determined specific optical rotations. $\left([\alpha]_{365}^{4}=662.3^{\circ}\right) .^{6}$

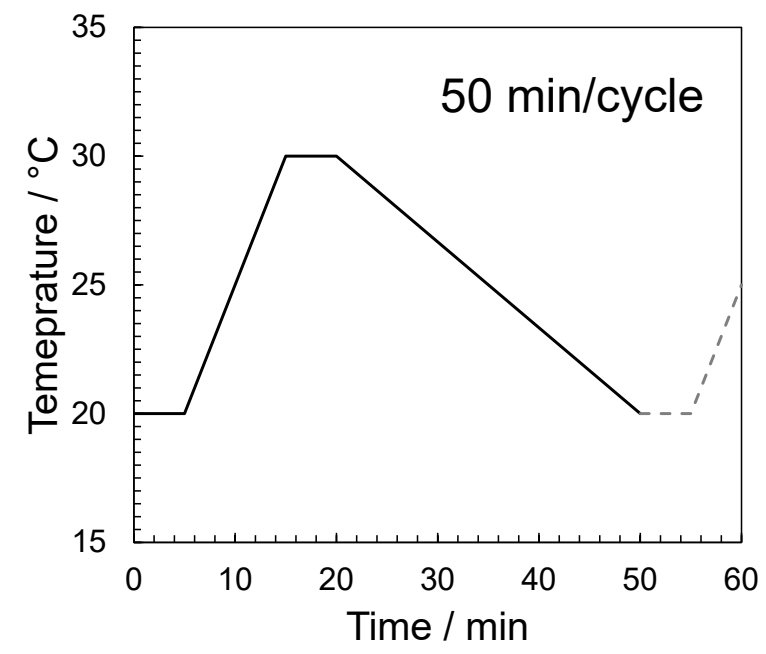

Figure 2. Temperature profile applied in the TCID experiments.

The SOAT process of $\mathbf{1}$ was carried out by applying the following procedure. A variable mass of powdered enantiopure seed crystals (prepared by grinding a single crystal) was added 
to a saturated solution of 1 in a $45 / 55$ (wt/wt) mixture of cyclohexane and ethyl acetate at $60{ }^{\circ} \mathrm{C}$ (mass fraction concentration $\mathrm{S}=22.2 \mathrm{wt} \%)$ in a $40-\mathrm{mL}$ vial $(\phi 27.5 \times 95 \mathrm{~mm}$, VWR France, France) for the 1-g scale experiment or a double-jacketed 150 -mL three-neck flask for the 10g scale experiment. The temperature was controlled by a thermostat (F25-HL Cryostat, JULABO GmbH, Germany). The mixture was then stirred at $500 \mathrm{rpm}$ by a cross magnetic stirrer throughout the experiment. After a 3-minute isotherm, the suspension was cooled to $30{ }^{\circ} \mathrm{C}$ over a period of about 85 min by using two types of cooling profiles, shown in Figure 3, hereafter referred to as cooling profiles $\mathrm{A}$ and $\mathrm{B}$. The experimental conditions are summarized in Table 1. The temperature of the solutions was monitored every $30 \mathrm{~s}$ with a data logger (LogStick LS450-T(K), Osaka Micro Computer Inc., Osaka, Japan) equipped with a thermocouple. The supersaturation of the solutions was monitored during cooling by sampling aliquots of the solution for gravimetric analyses. The crystals were collected by filtration and dried under a vacuum. The enantiomeric excess was determined by comparing the optical rotation measurements at $365 \mathrm{~nm}$ and $4{ }^{\circ} \mathrm{C}$ with the previously determined specific optical rotation.

Table 1. Experimental conditions for SOAT of 1 in 45/55 (wt/wt) mixture of cyclohexane and ethyl acetate.

\begin{tabular}{ccccccccc}
\hline Run & $\begin{array}{c}\text { Cooling } \\
\text { profile }\end{array}$ & $1 / \mathrm{g}$ & solvent $/ \mathrm{g}$ & $\mathrm{S} / \mathrm{wt} \%$ & $\mathrm{Seed} / \mathrm{mg}$ & $\mathrm{T}_{\text {initial }} /{ }^{\circ} \mathrm{C}$ & $\mathrm{T}_{\text {final }}{ }^{\circ} \mathrm{C}$ & Duration $/ \mathrm{min}$ \\
\hline 1 & A & 1.425 & 5.00 & 22.2 & 27.0 & 60 & 30 & 82 \\
2 & A & 1.426 & 5.00 & 22.2 & 32.4 & 60 & 30 & 82 \\
3 & A & 1.422 & 5.00 & 22.2 & 33.0 & 60 & 30 & 82 \\
4 & B & 1.428 & 5.01 & 22.2 & 10.9 & 60 & 30 & 85 \\
5 & B & 1.424 & 5.00 & 22.2 & 21.5 & 60 & 30 & 82 \\
6 & B & 1.427 & 5.01 & 22.2 & 30.8 & 60 & 30 & 83
\end{tabular}




\begin{tabular}{ccccccccc}
7 & B & 1.428 & 5.01 & 22.2 & 10.3 & 60 & 30 & 81 \\
\hline 8 & B & 9.990 & 35.01 & 22.2 & 60.8 & 60 & 30 & 89 \\
9 & B & 9.984 & 35.00 & 22.2 & 143.8 & 60 & 30 & 84 \\
10 & B & 9.945 & 34.96 & 22.2 & 35.1 & 60 & 30 & 85 \\
11 & A & 9.989 & 35.00 & 22.2 & 41.1 & 60 & 30 & 85 \\
\hline
\end{tabular}

With cooling profile A, temperature decreases linearly versus time (Figure 3 ) and the $\mathrm{C}_{\mathrm{T}} / \mathrm{C}_{30}$ ratio, $\mathrm{C}_{\mathrm{T}}$ and $\mathrm{C}_{30}$ being gravimetric solubility respectively at $\mathrm{T}$ and $30{ }^{\circ} \mathrm{C}$, changes drastically at the beginning of the process. Due to the solubility change, the supersaturation of the solution is expected to increase drastically, and primary nucleation of the counter enantiomer can occur. In contrast, as can be seen in cooling profile B, solubility linearly decreases with time in order to achieve a constant rate of crystal growth when the cooling rate was sufficiently slow to reach the solubility equilibrium at a specific temperature. In general, the rate of crystal growth in the fast cooling process depends on the diffusion and/or surface integration behavior of the molecule; therefore, this rate cannot be considered to be constant.
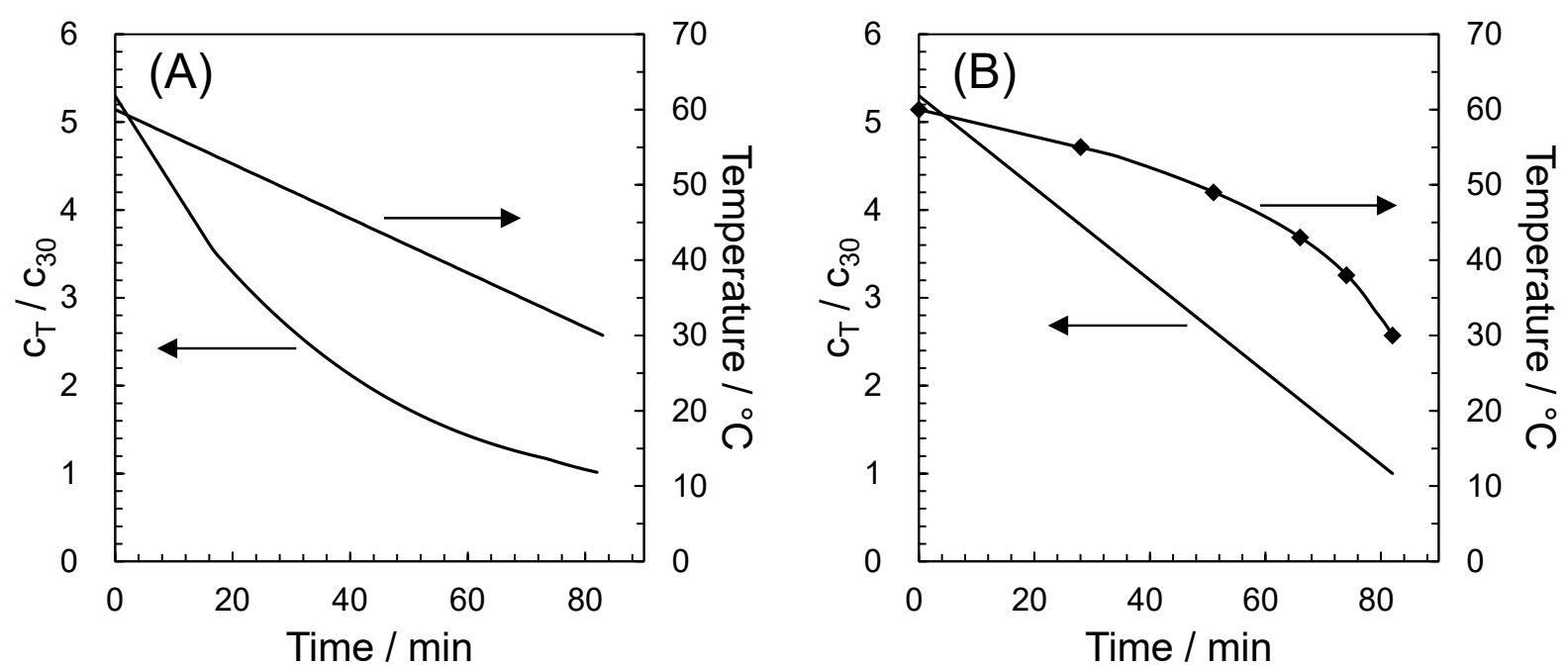
Figure 3. Two types of a cooling profile applied to SOAT of 1. (A) Linear cooling. (B) Solubility-controlled cooling; $\mathrm{c}_{\mathrm{T}}$ : saturated concentration at temperature $\mathrm{T}\left[{ }^{\circ} \mathrm{C}\right]$. Symbols in profile B are actual input points used in the temperature program of the thermostat.

\section{Results and Discussion}

Figure 4 shows the solubility and $k_{1}$ values of 1 as a function of temperature in an azeotropic mixture of ethyl acetate and cyclohexane $(45 / 55 \mathrm{wt} / \mathrm{wt})$. As can be seen from Figure 4, the solubility variation is small from $10-30{ }^{\circ} \mathrm{C}$ but increases abruptly from $30{ }^{\circ} \mathrm{C}$ onward. This behavior suggests the existence of a metastable miscibility gap, at higher or lower temperatures, also called submerged liquid demixing or the metastable oiling-out phenomenon. ${ }^{49}$ Therefore, seeded crystallization is well suited for this compound in order to avoid liquid demixing which may cause high supersaturation in one of the two liquids and thus uncontrolled crystallization. Racemization kinetic constants $k_{1}$ obtained by polarimetry measurements ${ }^{48}$ have been used to plot an Arrhenius’s graph, and the Gibbs free energy of activation $(\Delta \mathrm{G} \ddagger)$ was found to be 17.1 $\mathrm{kcal} \cdot \mathrm{mol}^{-1}$. In general, a torsion rotation energy barrier lower than $20-25 \mathrm{kcal} \cdot \mathrm{mol}^{-1}$ can show the interconversion within a few hours around room temperature. ${ }^{50}$ Thus, this value indicates that racemization in the solution is sufficiently fast to facilitate the development of a deracemization process during a reasonable period of time. Details of the solubility data and $k_{1}$ are given in the Supporting Information. 


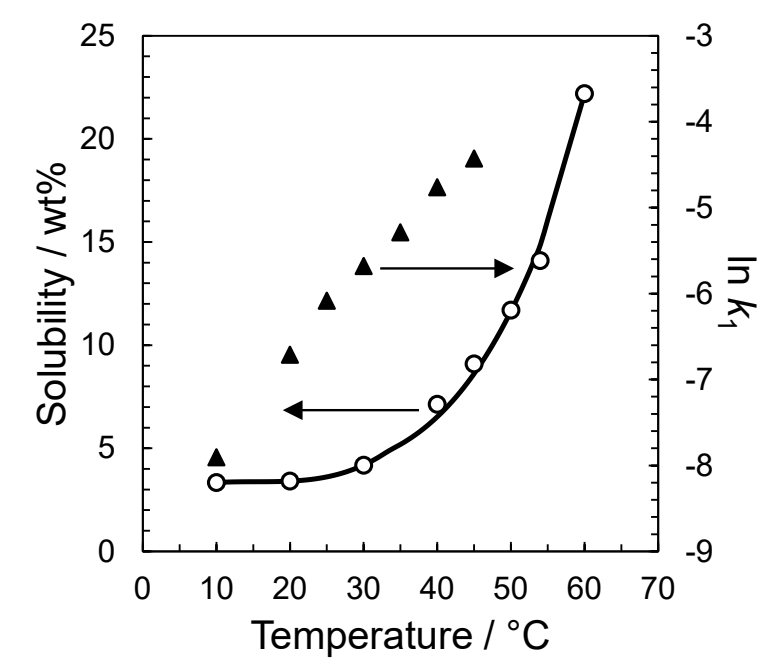

Figure 4. Racemization rate constants $(\Delta)$ and solubility curve of $\mathbf{1}(0)$ in the azeotropic mixture of cyclohexane and ethyl acetate.

In the present study, the productivity was calculated using Eq. 1 in which the volume of the solution (calculated using a solvent density of $0.856 \mathrm{~g} \mathrm{~mL}^{-1}$ and the measured mass at $20{ }^{\circ} \mathrm{C}$ ) was used instead of the suspension volume. To compare process robustness of TCID and SOAT, the yield was calculated using Eq. 2:

$$
\text { Yield }[\%]=\frac{m_{\text {crop }} \times e e_{\text {final }}-m_{\text {seeds }}}{m-m_{\text {solute, final }}} \times 100 \quad \text { (Eq. 2) }
$$

where $m$ and $m_{\text {solute, final }}$ represent the total mass of $\mathbf{1}$ and the mass of the solute in the saturated solution at the final temperature, respectively.

In general, crystallization yield does not consider the mass of the final solute which remains in solution since it can be varied by changing the operating conditions. Thorough optimization of the operating conditions would, therefore, be necessary for comparison of such factors for different processes is beyond the scope of this study. The yield should be $100 \%$ when the mass of collected crystals is the same as the theoretically affordable mass (i.e. taking into account 
the mass of the solute that remains solvated at the final temperature. Thus, the yield can be considered as a factor for determining process robustness.

Figure 5 displays the enantiomeric excesses (ees) of the collected crystals of $\mathbf{1}$ as functions of time during TCID experiments, while Table 2 summarizes the suspension density, the deracemization time (which is the time required to reach $95 \% e e$ from $0 \% e e$ ), and the process productivity. As shown in Figure 5, a larger suspension density resulted in a longer deracemization time. Although the process productivity for the $144-\mathrm{mg} \cdot \mathrm{mL}^{-1}$ suspension density was $10 \%$ lower than in the other cases, there was no significant difference in this range of suspension density. Thus, the process productivity of TCID can be regarded as being an independent factor affecting the suspension density, ranging from $10-150 \mathrm{mg} \cdot \mathrm{mL}^{-1}$. A higher suspension density than these conditions may give rise to an issue with the homogeneity of the system, while the suspension density would not be an independent factor from the process productivity. Hereafter, the average value, $0.67 \mathrm{~g} \cdot \mathrm{h}^{-1} \cdot \mathrm{L}^{-1}$, is used as the process productivity of TCID for comparison.

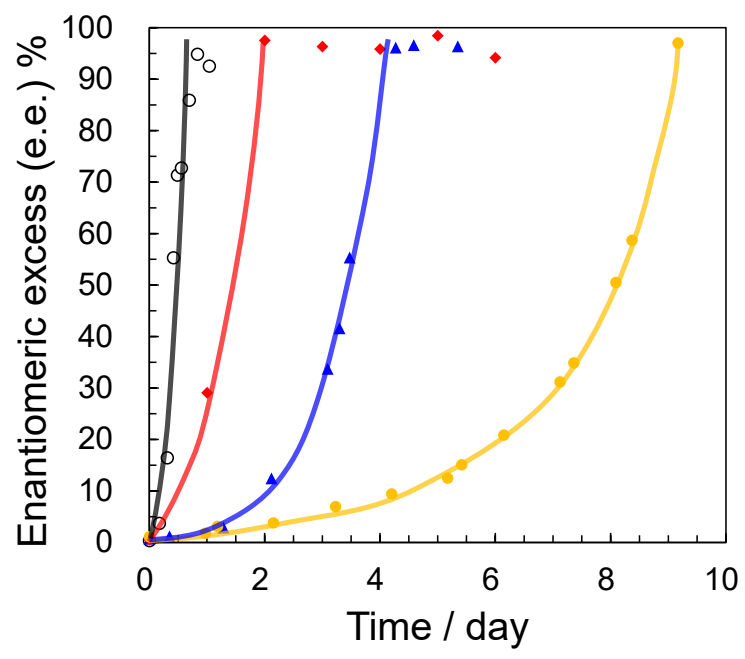

Figure 5. The enantiomeric excess of the collected crystals of 1 as a function of time during temperature cycle deracemization experiments in the azeotropic mixture of ethyl acetate and 
cyclohexane. Symbols indicate the suspension density. Black: $14.4 \mathrm{mg} \cdot \mathrm{mL}^{-1}$, Red: 36.0 $\mathrm{mg} \cdot \mathrm{mL}^{-1}$, Blue: $72.0 \mathrm{mg} \cdot \mathrm{mL}^{-1}$, Yellow: $144 \mathrm{mg} \cdot \mathrm{mL}^{-1}$. The lines are the guide for the eye.

Table 2. Summary of suspension density, deracemization time, and process productivity.

\begin{tabular}{ccccc}
\hline Suspension density $\rho / \mathrm{mg} \cdot \mathrm{mL}^{-1}$ & Deracemization time $/ \mathrm{h}$ & $e e_{\text {final }}[\%]$ & Productivity $/ \mathrm{g} \cdot \mathrm{h}^{-1} \cdot \mathrm{L}^{-1}$ & Yield[\%] \\
\hline 14.4 & 20 & 96 & 0.68 & $>95$ \\
36.0 & 48 & 98 & 0.71 & $>95$ \\
72.0 & 102 & 97 & 0.67 & $>95$ \\
144 & 220 & 97 & 0.62 & $>95$ \\
\hline
\end{tabular}

The solubility measurements were used to develop the SOAT process of 1 (see the experimental section for more details). The experimental results are summarized in Table 3.

Table 3. Summary of the experimental results of SOAT crystallization.

\begin{tabular}{cccccc}
\hline Run & Cooling profile & $m_{\text {crop }} / \mathrm{g}$ & $e e_{\text {final }}[\%]$ & Productivity $/ \mathrm{g} \mathrm{h}^{-1} \mathrm{~L}^{-1}$ & Yield [\%] \\
\hline 1 & A & 1.208 & 4 & 3 & 2 \\
2 & A & 1.211 & 26 & 35 & 23 \\
3 & A & 1.220 & 5 & 3.5 & $<1$ \\
4 & B & 1.205 & 87 & 125 & 86 \\
5 & B & 1.219 & 93 & 139 & 92 \\
6 & B & 1.206 & 97 & 141 & 84 \\
7 & B & 1.188 & 89 & 133 & 75 \\
\hline 8 & B & 8.317 & 77 & 104 & 80 \\
9 & B & 8.360 & 83 & 118 & 85 \\
10 & B & 8.432 & 85 & 124 & 51 \\
\hline
\end{tabular}

The mass of the crystals collected after Runs 1-3 (performed using linear cooling) was almost equal to the maximum value, (i.e., the crystallized mass accounts for the solubility difference between the initial and final temperature). However, the average enantiomeric excess was only $12 \%$. Because of this low enantiomeric excess, the yield was also low. Although the productivities of Runs 1-3 were higher than those obtained for TCID for the same solvent $\left(0.67 \mathrm{~g} \mathrm{~h}^{-1} \mathrm{~L}^{-1}\right)$, additional enantio-purification would be needed to achieve enantiopurity, which is undesirable. 
To understand the reason for this low enantiomeric excess, we performed a 10-g scale SOAT experiment (Run 11 in Tables 1 and 2) and monitored the enantiomeric excess of the crystal during the process. As shown in Figure 6a, the crystal enantiomeric excess starts to drop at the beginning of the experiment. Because the $\mathrm{C}_{\mathrm{T}} / \mathrm{C}_{30}$ ratio decreases rather abruptly in this temperature domain (Figure 3), this is likely to cause uncontrolled primary nucleation of the counter-enantiomer upon cooling. This is further supported by Figure $6 \mathrm{~b}$, which depicts the supersaturation profile of the solution and shows that the supersaturation remained quite high $(\sim 1.2)$ during the process. The increase in the supersaturation at the end of the experiment is likely due to the crystallization rate slowing down at lower temperatures and which cannot adapt to the corresponding temperature change.
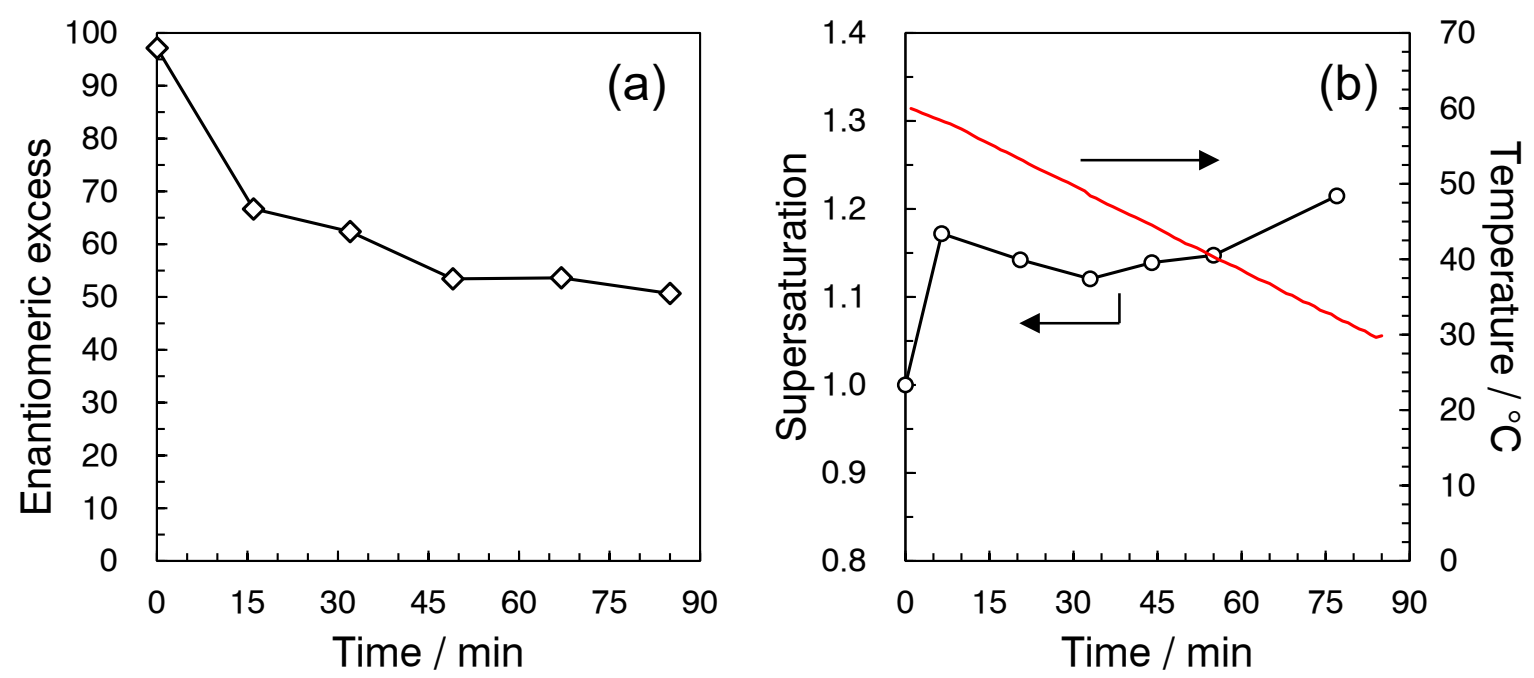

Figure 6. (a) Enantiomeric excess (ee) values of the collected crystals of compound 1. (b) Temperature profile of SOAT experiments with linear cooling and supersaturation as a function of time during SOAT experiments with linear cooling (cooling profile A).

By contrast, the crystals obtained by solubility-controlled cooling (cooling profile B) exhibited high enantiomeric excesses (Runs 4-11, Table 3), and showed moderate yields (75$95 \%$ ) compared to those obtained by TCID (>99\%). The absolute configuration of the resulting 
crystals was also identical to that of the seed crystals. Accordingly, the monitoring of the crystal enantiomeric excess (Figure 7a) showed that the initial enantiomeric excess of the seeds was almost constant throughout the process. The cooling profile applied to these experiments implies a slow cooling rate at the beginning of the process, which reduces the primary nucleation of the counter enantiomer (Figure 7b). The cooling profile maintains the supersaturation at close to 1.0 during the whole process (the crystal growth of the seeds is sufficiently fast to compensate for the moderated supersaturation increase).
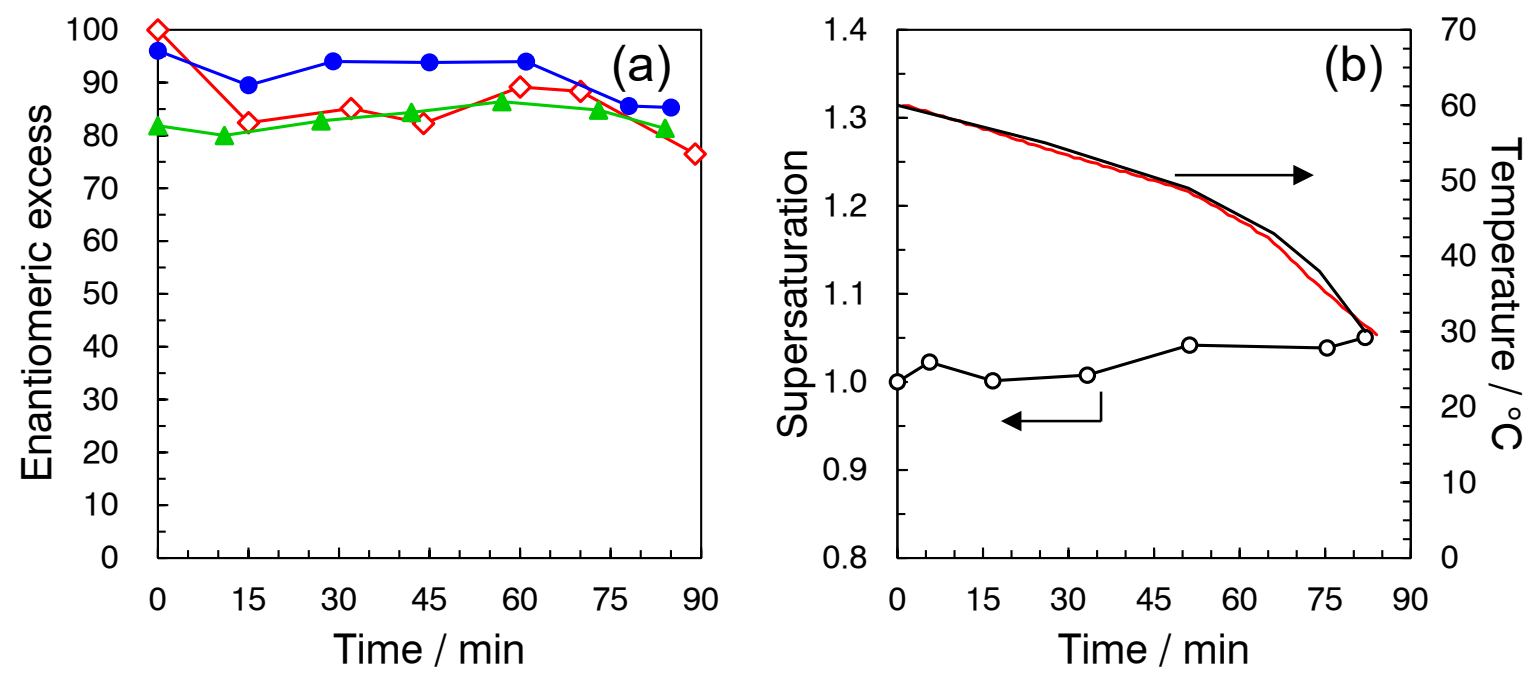

Figure 7. (a) Enantiomeric excess (ee) values of the collected crystals of 1. Each line corresponds to Runs 8, 9, and 10. (b) Temperature profile of SOAT experiments with solubility-controlled cooling (black line: ideal profile, red line: observed profile), and supersaturation as a function of time during SOAT experiments with solubility-controlled cooling (cooling profile B).

The average productivity of TCID for 1 was $0.67 \mathrm{~g} \mathrm{~h}^{-1} \mathrm{~L}^{-1}$, while that of SOAT at the same scale (i.e., runs 4-7) was an average of $135 \mathrm{~g} \mathrm{~h}^{-1} \mathrm{~L}^{-1}$. This productivity difference is a result of the process time: although this depends on the scale of the crystallizer, TCID is generally performed in a time frame of several hours to some days, whereas SOAT can be performed in 
a few hours because it requires only a single cooling process. Moreover, for the $10 \mathrm{-g}$ scale experiment (Run 8-10), without sophisticated optimization (i.e., the mass of the compound and solvent increased proportionally), the time required for the process remained the same, with a decrease in productivity of only $10 \%$ compared to the 1 -g scale. Therefore, scaling-up for industrial applications is expected to be relatively easy.

Figure 8a shows a SEM image of crop crystal after cooling profile A. The crystals exhibited a size distribution $10-100 \mu \mathrm{m}$, while small particles adhered to those crystals. Those small particles could have been produced by the primary nucleation during the process, implying that primary nucleation frequently occurred during cooling profile A. Since the chirality of the primary nucleation could not be controlled, the nucleation included both enantiomers. Therefore, the enantiomeric excess dropped during cooling profile A. By contrast, the relatively large crystals $(100-1000 \mu \mathrm{m})$ are found in the crop after cooling profile B, as shown in Figure 8b. These crystals can be regarded as grown seeded crystals. As scars of abrasions was visible on the large crystals, abrasion phenomena might also occur during the process. Since abrasion produces small crystals which have the same chirality as the original crystals, the resulting crystals do not cause a decrease in the enantiomeric excess. Smaller crystals could be generated by the abrasion process of the large crystals or by secondary nucleation. 

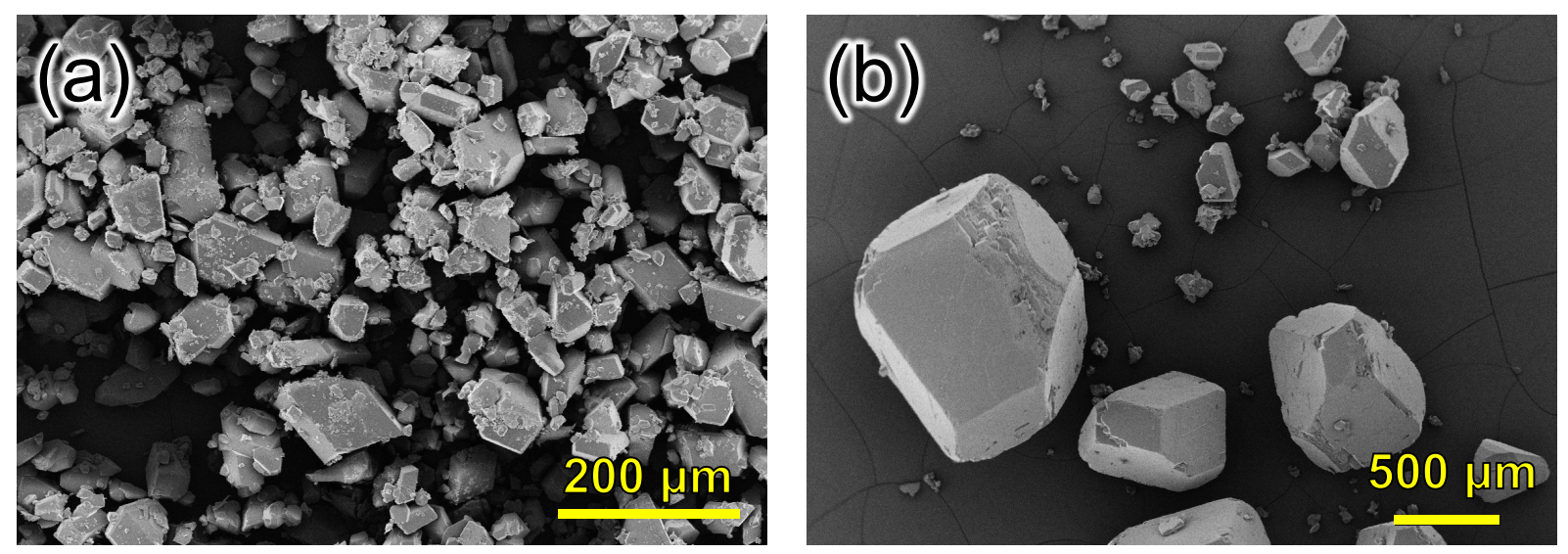

Figure 8. (a) SEM images of collected crystals after (a) the cooling profile A, and (b) the cooling profile B.

\section{Conclusion}

We performed SOAT on atropoisomeric naphthamide 1, which exhibits spontaneous racemization in solution in the absence of any racemization reagent, with two different temperature profiles at $1-\mathrm{g}$ and $10-\mathrm{g}$ scales. Monitoring of the supersaturation of the solution and enantiomeric excess of the solid phase upon cooling highlighted that the so-called "solubility-controlled cooling" is better suited to producing high enantiomeric excesses of crystals. Moreover, we showed that the productivity of SOAT is considerably higher than that of TCID. The present study was the first to compare the productivities of SOAT and TCID for the same compound, naphthamide 1. In addition, we found that scaling up by a factor of 10 was also feasible. Although SOAT requires enantiomerically pure seed crystals, it could feasibly be part of an efficient process in the future. For example, TCID could be used to prepare enantiopure crystals, which could then be used as seed crystals in a SOAT process. Alternatively, a continuous SOAT process could be envisaged as a more productive technique than TCID. 


\section{ASSOCIATED CONTENT}

Supporting Information. Solubility data and racemization kinetic constants of $\mathbf{1}$ (PDF).

\section{AUTHOR INFORMATION}

\section{Corresponding Author}

* E-mail: gerard.coquerel@univ-rouen.fr

\section{ORCID}

Ryusei Oketani: 0000-0001-7860-2456

Clément Brandel: 0000-0002-7747-0823

Gérard Coquerel: 0000-0001-8977-8676

\section{Author Contributions}

The manuscript was written through the contributions of all authors. All authors have given approval to the final version of the manuscript.

\section{Funding Sources}

This research received funding as part of a CORE project (October 2016-September 2020) from the Horizon 2020 Research and Innovation Programme of the European Union under Marie Sklodowska-Curie Grant Agreement No. 722456 CORE ITN.

\section{Notes}

The authors declare no competing financial interests.

\section{ACKNOWLEDGMENT}


The authors thank the Horizon 2020 Research and Innovation Programme and Marie

Sklodowska Curie Grant for funding this research.

\section{REFERENCES}

(1) Suwannasang, K.; Flood, A. E.; Coquerel, G. A Novel Design Approach to Scale Up the Temperature Cycle Enhanced Deracemization Process: Coupled Mixed-Suspension Vessels. Cryst. Growth Des. 2016, 16, 6461-6467.

(2) Noorduin, W. L.; Van Der Asdonk, P.; Bode, A. A. C.; Meekes, H.; Van Enckevort, W. J. P.; Vlieg, E.; Kaptein, B.; Van Der Meijden, M. W.; Kellogg, R. M.; Deroover, G. Scaling Up Attrition-Enhanced Deracemization by Use of an Industrial Bead Mill in a Route to Clopidogrel (Plavix). Org. Process Res. Dev. 2010, 14, 908-911.

(3) van der Meijden, M. W.; Leeman, M.; Gelens, E.; Noorduin, W. L.; Meekes, H.; van Enckevort, W. J. P.; Kaptein, B.; Vlieg, E.; Kellogg, R. M. Attrition-Enhanced Deracemization in the Synthesis of Clopidogrel - A Practical Application of a New Discovery. Org. Process Res. Dev. 2009, 13, 1195-1198.

(4) Coquerel, G. Preferential Crystallization. In Topics in Current Chemistry; 2006; Vol. 269, pp 1-51.

(5) Rachwalski, M.; Vermue, N.; Rutjes, F. P. J. T. Recent Advances in Enzymatic and Chemical Deracemisation of Racemic Compounds. Chem. Soc. Rev. 2013, 42, 9268 9282.

(6) Oketani, R.; Hoquante, M.; Brandel, C.; Cardinael, P.; Coquerel, G. Practical Role of Racemization Rates in Deracemization Kinetics and Process Productivities. Cryst. Growth Des. 2018, 18, 6417-6420.

(7) Belletti, G.; Meekes, H.; Rutjes, F. P. J. T.; Vlieg, E. Role of Additives during Deracemization Using Temperature Cycling. Cryst. Growth Des. 2018, 18, 66176620 .

(8) Breveglieri, F.; Maggioni, G. M.; Mazzotti, M. Deracemization of NMPA via Temperature Cycles. Cryst. Growth Des. 2018, 18, 1873-1881.

(9) Uchin, R.; Suwannasang, K.; Flood, A. E. Model of Temperature Cycle-Induced Deracemization via Differences in Crystal Growth Rate Dispersion. Chem. Eng. Technol. 2017, 40, 1252-1260.

(10) Li, W. W.; Spix, L.; De Reus, S. C. A.; Meekes, H.; Kramer, H. J. M.; Vlieg, E.; Ter Horst, J. H. Deracemization of a Racemic Compound via Its Conglomerate-Forming Salt Using Temperature Cycling. Cryst. Growth Des. 2016, 16, 5563-5570.

(11) Suwannasang, K.; Flood, A. E.; Rougeot, C.; Coquerel, G. Use of Programmed Damped Temperature Cycles for the Deracemization of a Racemic Suspension of a Conglomerate Forming System. Org. Process Res. Dev. 2017, 21, 623-630.

(12) Rougeot, C.; Hein, J. E. Application of Continuous Preferential Crystallization to Efficiently Access Enantiopure Chemicals. Org. Process Res. Dev. 2015, 19, 1809 1819.

(13) Coquerel, G.; Mahieux, J.; Gerandon, F-X. Method for the resolution of baclofen salts. WO 2018/015677 A1, January 25, 2018.

(14) Eicke, M. J.; Levilain, G.; Seidel-Morgenstern, A. Efficient Resolution of Enantiomers by Coupling Preferential Crystallization and Dissolution. Part 2: A Parametric Simulation Study to Identify Suitable Process Conditions. Cryst. Growth Des. 2013, $13,1638-1648$.

(15) Galan, K.; Eicke, M. J.; Elsner, M. P.; Lorenz, H.; Seidel-Morgenstern, A. Continuous Preferential Crystallization of Chiral Molecules in Single and Coupled Mixed- 
Suspension Mixed-Product-Removal Crystallizers. Cryst. Growth Des. 2015, 15, 1808-1818.

(16) Engwerda, A. H. J.; van Schayik, P.; Jagtenberg, H.; Meekes, H.; Rutjes, F. P. J. T.; Vlieg, E. Deracemization of a Racemic Compound by Using Tailor-Made Additives. Chem. - A Eur. J. 2018, 24, 2863-2867.

(17) Rougeot, C.; Guillen, F.; Plaquevent, J. C.; Coquerel, G. Ultrasound-Enhanced Deracemization: Toward the Existence of Agonist Effects in the Interpretation of Spontaneous Symmetry Breaking. Cryst. Growth Des. 2015, 15, 2151-2155.

(18) Asymmetric Transformation. In IUPAC Compendium of Chemical Terminology; IUPAC: Research Triagle Park, NC; Vol. 2193, p 2200.

(19) Inagaki, M.; Hiratake, J.; Nishioka, T.; Oda, J. One-Pot Synthesis of Optically Active Cyanohydrin Acetates from Aldehydes via Lipase-Catalyzed Kinetic Resolution Coupled with in Situ Formation and Racemization of Cyanohydrins. J. Org. Chem. 1992, 57, 5643-5649.

(20) Smrcina, M.; Polakova, J.; Vyskocil, S.; Kocovsky, P. Synthesis of Enantiomerically Pure Binaphthyl Derivatives. Mechanism of the Enantioselective, Oxidative Coupling of Naphthols and Designing a Catalytic Cycle. J. Org. Chem. 1993, 58, 4534-4538.

(21) Solladié, G.; Lohse, O. New Reagent for the Optical Resolution of Ketones: (-) (1R, 2R, 5R)-5-Methyl-2-(1-Mercapto-1-Methylethy)-Cyclohexanol. Application to Trans Dimethyl Cyclopentanone-3,4-Dicarboxylate. Tetrahedron: Asymmetry 1993, 4, 15471552.

(22) Soloshonok, V. A.; Kukhar, V. P.; Galushko, S. V.; Svistunova, N. Y.; Avilov, D. V; Kuz'mina, N. A.; Raevski, N. I.; Struchkov, Y. T.; Pysarevsky, A. P.; Belokon, Y. N. General Method for the Synthesis of Enantiomerically Pure $\beta$-Hydroxy- $\alpha$-Amino Acids, Containing Fluorine Atoms in the Side Chains. Case of Stereochemical Distinction between Methyl and Trifluoromethyl Groups. X-Ray Crystal and Molecular Structure of the Nic. J. Chem. Soc., Perkin Trans. 1 1993, No. 24, 31433155.

(23) Biscarini, P.; Franca, R.; Kuroda, R. Chiral Discrimination of Complexes with D3 Symmetry. Synthesis and Characterization of Tris $\left\{\mathrm{O}, \mathrm{O}^{\prime}-\mathrm{Bis}[(+)(\mathrm{S})-2-\mathrm{Methylbutyl}]\right.$ Dithiophosphato\} chromium(III) Complexes (.LAMBDA..DELTA.) $\{\mathrm{Cr}[(+)(\mathrm{S})(\mathrm{S}) \mathrm{Mebdtp}] 3\}$ and .LAMBDA.-(-)589-, and .DELTA. $(+) 589\{\mathrm{Cr}[(+)(\mathrm{S})($ S. Inorg. Chem. 1995, 34, 4618-4626.

(24) Noyori, R.; Tokunaga, M.; Kitamura, M. Stereoselective Organic Synthesis via Dynamic Kinetic Resolution. Bull. Chem. Soc. Jpn. 1995, 68, 36-55.

(25) Vedejs, E.; Fields, S. C.; Lin, S.; Schrimpf, M. R. Asymmetric Transformation in Boron Ate Complexes of Amino Acids. J. Org. Chem. 1995, 60, 3028-3034.

(26) Pabel, M.; Willis, A. C.; Wild, S. B. Attempted Resolution of Free ( \pm )Chlorophenylisopropylphosphine. Tetrahedron: Asymmetry 1995, 6, 2369-2374.

(27) van der Deen, H.; Cuiper, A. D.; Hof, R. P.; van Oeveren, A.; Feringa, B. L.; Kellogg, R. M. Lipase-Catalyzed Second-Order Asymmetric Transformations as Resolution and Synthesis Strategies for Chiral 5-(Acyloxy)-2(5 H )-Furanone and Pyrrolinone Synthons. J. Am. Chem. Soc. 1996, 118, 3801-3803.

(28) Pabel, M.; Willis, A. C.; Wild, S. B. First Resolution of a Free Fluorophosphine Chiral at Phosphorus. Resolution and Reactions of Free and Coordinated $( \pm)$ Fluorophenylisopropylphosphine. Inorg. Chem. 1996, 35, 1244-1249.

(29) Pabel, M.; Willis, A. C.; Wild, S. B. First Resolution of a Free Fluorophosphine Chiral at Phosphorus. Resolution and Reactions of Free and Coordinated $( \pm)-$ Fluorophenylisopropylphosphine. Inorg. Chem. 1996, 35, 1244-1249. 
(30) Bader, A.; Pabel, M.; Willis, A. C.; Wild, S. B. First Resolution of a Free Secondary Phosphine Chiral at Phosphorus and Stereospecific Formation and Structural Characterization of a Homochiral Secondary Phosphine-Borane Complex. Inorg. Chem. 1996, 35, 3874-3877.

(31) Yamada, K.; Ishii, R.; Nakagawa, H.; Kawazura, H. A Second-Order Asymmetric Transformation of Racemic 2-Hydroxymethyl[5]Thiaheterohelicene into a Single Enantiomer upon Uptake by Bovine Serum Albumin. Tetrahedron: Asymmetry 1996, 7, 737-746.

(32) Hockless, D. C. R.; Gugger, P. A.; Leung, P.-H.; Mayadunne, R. C.; Pabel, M.; Bruce Wild, S. Facile Interconversions between Diastereomers of Chloro-Bridged Palladium(II) Dimers of Orthometallated ( \pm )-Dimethyl[1-(1-Naphthyl)Ethyl]Amine. Tetrahedron 1997, 53, 4083-4094.

(33) Czollner, L.; Frantsits, W.; Küenburg, B.; Hedenig, U.; Fröhlich, J.; Jordis, U. New Kilogram-Synthesis of the Anti-Alzheimer Drug (-)-Galanthamine. Tetrahedron Lett. 1998, 39, 2087-2088.

(34) Maryanoff, C. A.; Scott, L.; Shah, R. D.; Villani Jr, F. J. A Crystallization-Induced Asymmetric Transformation to Prepare (R)-4-Chlorophenylalanine Methyl Ester. Tetrahedron: Asymmetry 1998, 9, 3247-3250.

(35) Kita, M.; Yamanari, K. The Effect of Counter Cations on Second-Order Asymmetric Transformations in Fac- $\Delta$ - and $\Lambda$-Tris(R-Cysteinato-N,S )Cobaltate(III) Complexes and the Kinetics of Mutarotation. J. Chem. Soc. Dalt. Trans. 1999, No. 8, 1221-1226.

(36) Yamanari, K.; Ito, R.; Yamamoto, S.; Fuyuhiro, A. Diastereomeric Separation of $\left[\left\{\mathrm{M}\left(\mathrm{Cp}^{*}\right)(\mathrm{Ado})\right\} 3\right] 3+(\mathrm{M}=\mathrm{RhIII}, \mathrm{IrIII} ;$ Ado = Adenosinato $):$ Crystal Structure of an Inclusion Compound $\left[\left\{\mathrm{Rh}\left(\mathrm{Cp}^{*}\right)(\mathrm{Ado})\right\} 3\right](\mathrm{CF} 3 \mathrm{SO} 3) 3 \cdot \mathrm{MeOH}$. Chem. Commun. 2001, No. 15, 1414-1415.

(37) Yamanari, K.; Ito, R.; Yamamoto, S.; Konno, T.; Fuyuhiro, A.; Kobayashi, M.; Arakawa, R. Diastereomeric Separations and Crystal Structures of Rhodium(Iii) and Iridium(Iii) Complexes Containing Adenosine and Related NucleosidesElectronic Supplementary Information (ESI) Available: 1H NMR and CD Spectra. See Http://Www.Rsc.Org/Suppdata/Dt/B2/B20. Dalt. Trans. 2003, No. 3, 380-386.

(38) Tsubaki, K.; Miura, M.; Morikawa, H.; Tanaka, H.; Kawabata, T.; Furuta, T.; Tanaka, K.; Fuji, K. Synthesis of Optically Active Oligonaphthalenes via Second-Order Asymmetric Transformation. J. Am. Chem. Soc. 2003, 125, 16200-16201.

(39) Kostyanovsky, R. G.; Kostyanovsky, V. R.; Kadorkina, G. K.; Lyssenko, K. A. Asymmetric Three-Coordinated Nitrogen Compounds: Spontaneous Resolution and Absolute Asymmetric Synthesis. Mendeleev Commun. 2003, 13, 111-113.

(40) Biscarini, P.; Benedetti, M.; Ferranti, F.; Kuroda, R.; Foresti, E.; Sabatino, P. Transfer of Chirality by Dithiophosphate Ligands and Chiral Discrimination in the Stereoselective Formation of Square-Planar Ni(II) Complexes. Chirality 2004, 16, 251-262.

(41) Chandrasekhar, S.; Chopra, D.; Guru Row, T. N.; Hota, R.; Kanai, T. Oscillation of Spontaneously Generated Optical Activity in ( \pm )-1-(p-Nitrobenzoyloxy)Indane Solutions: 'Serial SN2 Reactions' in Aggregates Supported by the Crystal Structure. Frozen SN2 Transition States and Enantioselective Distortions. J. Mol. Struct. 2005, $738,113-116$.

(42) Chandrasekhar, S.; Gorla, S. K. Novel Cis-trans Enantiomeric Conglomerates: Triage and Absolute Configurations via Anomalous X-Ray Scattering. A Photochemical Second Order Asymmetric Transformation. Tetrahedron: Asymmetry 2006, 17, $2247-$ 2251. 
(43) Biscarini, P.; Benedetti, M.; Kuroda, R.; Ferranti, F. Transfer of Chirality in Complexes WithD3 Symmetry: Kinetics of the Formation Reaction of Chiral Tris[O,O'-Bis(2-Methylbutyl)Dithiophosphato]Chromium(III) Complexes $(\Lambda, \Delta)$ [Cr $\{( \pm)-M e b d t p\} 3], \Delta-(+) 589-$ and $\Lambda-(-) 589-[\operatorname{Cr}\{(+)-(\mathrm{S})(\mathrm{S})-M e b d t p\} 3]$. Eur. J. Inorg. Chem. 2006, 2006, 3167-3176.

(44) Chandrasekhar, S. Molecular Homochirality and the Parity-Violating Energy Difference. A Critique with New Proposals. Chirality 2008, 20, 84-95.

(45) Faigl, F.; Mátravölgyi, B.; Holczbauer, T.; Czugler, M.; Madarász, J. Resolution of 1[2-Carboxy-6-(Trifluoromethyl)Phenyl]-1H-Pyrrole-2-Carboxylic Acid with Methyl (R)-2-Phenylglycinate, Reciprocal Resolution and Second Order Asymmetric Transformation. Tetrahedron: Asymmetry 2011, 22, 1879-1884.

(46) Siedlecka, R. Recent Developments in Optical Resolution. Tetrahedron 2013, 69, 6331-6363.

(47) Gonella, S.; Levilain, G.; Coquerel, G. Racemizable Systems Crystallizing as Conglomerate and Spontaneous Symmetry Breaking. J. Therm. Anal. Calorim. 2011, 103, 125-129.

(48) Ebbers, E. J.; Ariaans, G. J. A.; Houbiers, J. P. M.; Bruggink, A.; Zwanenburg, B. Controlled Racemization of Optically Active Organic Compounds: Prospects for Asymmetric Transformation. Tetrahedron 1997, 53, 9417-9476.

(49) Brandel, C.; Gbabode, G.; Cartigny, Y.; Martin, C.; Gouhier, G.; Petit, S.; Coquerel, G. Crystal Growth, Structure, and Polymorphic Behavior of an Ionic Liquid: Phthalate Derivative of N -Butyl, N -Methylimidazolium Hexafluorophosphate. Chem. Mater. 2014, 26, 4151-4162.

(50) Laplante, S. R.; Fader, L. D.; Fandrick, K. R.; Fandrick, D. R.; Hucke, O.; Kemper, R.; Miller, S. P. F.; Edwards, P. J. Assessing Atropisomer Axial Chirality in Drug Discovery and Development. J. Med. Chem. 2011, 54, 7005-7022. 